\title{
A look ahead for 2014
}

\author{
David H Henry, MD, FACP
}

$\mathrm{W}$ elcome to The Journal of Community and Supportive Oncology, an expansion of The Journal OF SUPPORTIVE OnCOLOGY incorporating its sister publication, Community Oncology. We are excited about merging these two fine peer-reviewed publications to bring you the best of both journals in a dynamic publication that will enhance the parent journals' respective missions and services to the readers.

The Journal of Community and Supportive OnCOLOGY will be published monthly in print, rather than quarterly, as was the case with The Journal of Supportive Oncology, and will continue to be indexed in PubMed. The good news for authors especially is that JCSO will also have a published first online component that will allow authors to cite their articles before going to print. We also anticipate that monthly rather than quarterly print publishing, as was the case with THE JournaL of Supportive Oncology, will afford authors a more rapid publishing process for their manuscripts.

The features of the two journals will be merged and we invite you to go to www.editorialmanager.com/jso/ to submit your manuscripts under the following articles types: Original Reports, Review, How We Do It, Case Report, or Commentary - and tell your colleagues and residents about our publishing options as well. In addition, we will continue to publish the Community Translations columns, as well as our popular feature articles on practical biostatistics, technology, practice economics, and health policy, among others.

As part of this process, the Editorial Boards will also merge, and the circulation of the new Journal will be expanded to reflect the receivership of the two publications. I will be assisted by a distinguished group of Editors in guiding the JCSO through this transition: Jame Abraham, MD, director of the breast oncology program at Cleveland Clinic's Taussig Cancer Institute in Ohio; Linda D. Bosserman, MD, president of Wiltshire Oncology, Rancho Cucamonga, California; Howard A.
Burris III, MD, chief medical officer and executive director of the Drug Development Program at the Sarah Cannon Research Institute in Nashville, Tennessee; David Cella, $\mathrm{PhD}$, chair of the department of medical social sciences and director of the center for patient-centered outcomes at the Institute for Public Health and Medicine at Northwestern University's Feinberg School of Medicine in Chicago; Debra A. Patt, MD, MPH, of Texas Oncology in Austin and medical director of the Pathways Task Force and Healthcare Informatics for The US Oncology Network; and Thomas Strouse, $\mathrm{MD}$, medical director of the Stewart and Lynda Resnick Neuropsychiatric Hospital at UCLA Medical Center, Santa Monica, California.

True to our mission to enhance our editorial offerings, this issue of JCSO includes articles that look at current therapeutic and supportive aspects of care across the cancer spectrum. On pages 6 and 13, respectively, Buzaglo and colleagues present a qualitative study on understanding the experience of living with non-small-cell lung cancer, and DeMille et al report on vitamin D deficiency in the oncology setting. In the Review section, Schindler and Postow present a thorough review of options in the systemic treatment of metastatic melanoma (p. 20), and Rodriguez looks at biomarker testing for treating metastatic colorectal cancer and the role of the pathologist in community practice (p. 27). Community Translations features afatinib, which was recently approved for patients with metastatic NSCLC who have EGFR exon 19 deletions or exon 21 (L858R) substitution mutations (p. 4; Commentary, p. 2). Also included in this issue are feature articles on synthetic lethality and practical biostatistics, and a Case Report by Chakraborty on a rare co-occurrence of chronic myeloid leukemia and chronic lymphocytic leukemia (p. 33).

We invite you to continue as a reader of (and perhaps occasional contributor to), The Journal of Community and Supportive Oncology. On behalf of my Editors, I wish you the very best for 2014 .

JCSO 2014;12:1. C2014 Frontline Medical Communications Inc. DOI 10.12788/jcso.0001. 